\title{
The Spectrum of Angiographic Findings in Transitional Cell Carcinoma of the Kidney
}

\author{
KYUNG J. CHO, M.D., STEWART R. REUTER, M.D., PHILLIP R. HOSKINS, M.D. \\ The Departments of Radiology, University of Michigan, Medical Center, \\ Ann Arbor, Michigan 48109; V.A. Hospital, Martinez, Califomia 94553 and \\ St. Joseph Mency Hospital, Amn Arbor, Michigan 48104.
}

\section{PATIENT MATERIALS}

Renal angiography was performed in 20 patients with histologically proven transitional cell carcinomas of the kidney at Wayne County General Hospital, The University of Michigan Medical Center, and Ann Arbor St. Joseph Mercy Hospital between 1967 and 1975. In addition to conventional angiograms, six patients had pharmacoangiographic studies, four with epinephrine and two with Priscoline. There were 16 men and four women, with an average age of 59 years (range 21 to 89 years). All twenty patients had intravenous urograms; a diagnosis of transitional cell carcinoma could be made with a high level of confidence in ten. In an additional six patients the intravenous urogram revealed a nonfunctioning kidney. In the patients with nonfunctioning kidneys, retrograde urograms gave the diagnosis in the four patients in whom it was done.

\section{ANGIOGRAPHIC FINDINGS}

The angiographic abnormalities are summarized in Table 1. In five of the 20 patients $(25 \%)$ the diagnosis could be made neither in prospect nor retrospect. One of these patients had a large tumour mass occluding the main renal artery and the other four showed no angiographic abnormalities. The size of the tumours in the patients with normal angiograms ranged from $0.4 \mathrm{~cm}$ to $2.0 \mathrm{~cm}$ (1.1 cm average). Moreover, an angiogram done on the resected kidney in one of these patients failed to reveal any abnormality in spite of definite polypoid defects which has been demonstrated on the urogram. In four of the patients in whom the diagnosis was missed by angiography, the tumour involved primarily the calices and was situated within the renal parenchyma, while in one the lesion was found in the renal pelvis (Figure 1).

In the remaining 15 patients, a prospective diagnosis of transitional cell carcinoma was made because of a combination of the following angiographic findings:

1) Tumour vessels (Figure 2). All 15 patients had fine neovascularity, frequently arising from prominent pelviureteric arteries or from proximal renal artery branches in the region of the pelvis or calices. The number of tumour vessels present correlated roughly with the size of the lesion. A high quality angiogram with magnification technique, therefore, is an aid to correct diagnosis.

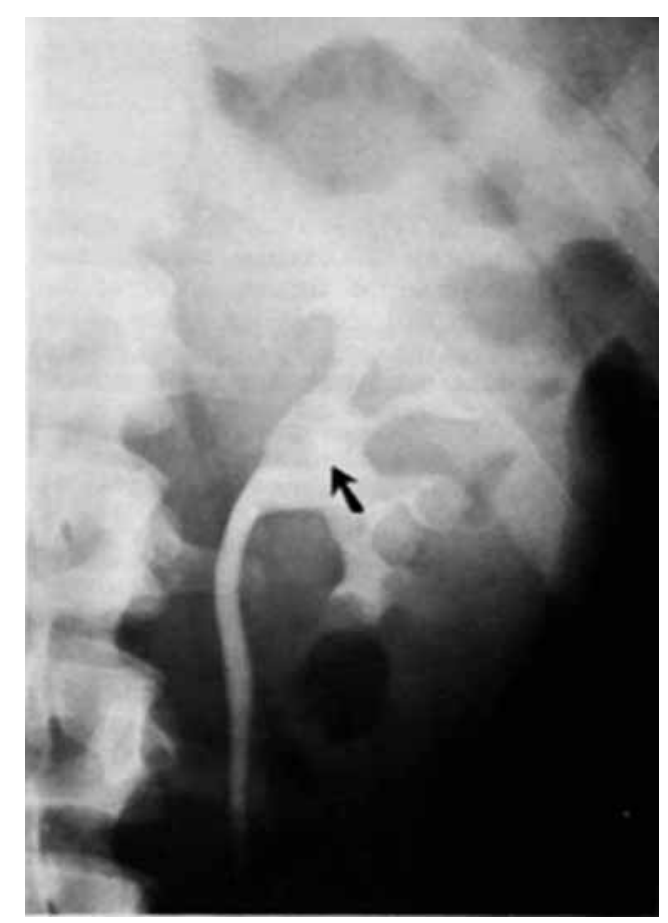

FIGURE 1A

FIGURE 1.-Urography and angiography in a 23 year old woman with gross hematuria. A $15 \mathrm{~cm}$ transitional cell carcinoma was found in the renal pelvis at operation. A. An intravenous urogram shows polypoid filling defects in the pelvis (arrow).

B. A renal angiogram demonstrates no abnormality. 


\section{K. J. CHO, S. R. REUTER AND P. R. HOSKINS}

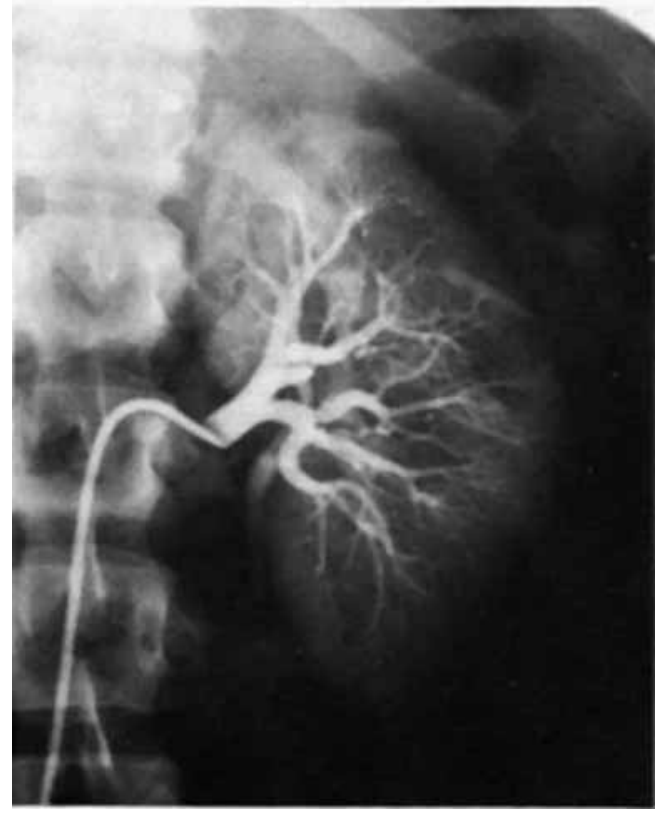

FIGURE 1B

2) Tumour stain (Figure 3). A faint, relatively homogenous increase in contrast accumulation was present through the tumour in 11 of the patients. This was best seen in the region of the renal pelvis during the capillary or venous phases. No vascular lakes nor arteriovenous shunts were observed in any patient.

3) Prominent pelviureteric arteries (Figure 3). The pelviureteric arteries were prominent in 13 patients. This finding alone, however, is nonspecific and may be seen in inflammatory disease of the renal pelvis or ureter.

4) Arterial encasement (Figures 2, 4). Renal and renal pelvic arteries were encased in ten patients. The encasement was the type caused by most carcinomas, characterized by abrupt changes in the course and caliber of arteries. This finding was most easily discerned in renal pelvic branches, but could also be found in those tumours which encased intrarenal arteries.

5) "Pruned tree" appearance of intrarenal arteries associated with an ill-defined defect in the nephrogram phase (Figure 4). This combination of findings was observed in only four patients and is caused by invasion of the renal parenchyma by the poorly vascularised transitional cell tumour.

6) Hydronephrosis (Figures 2, 3). Five of the

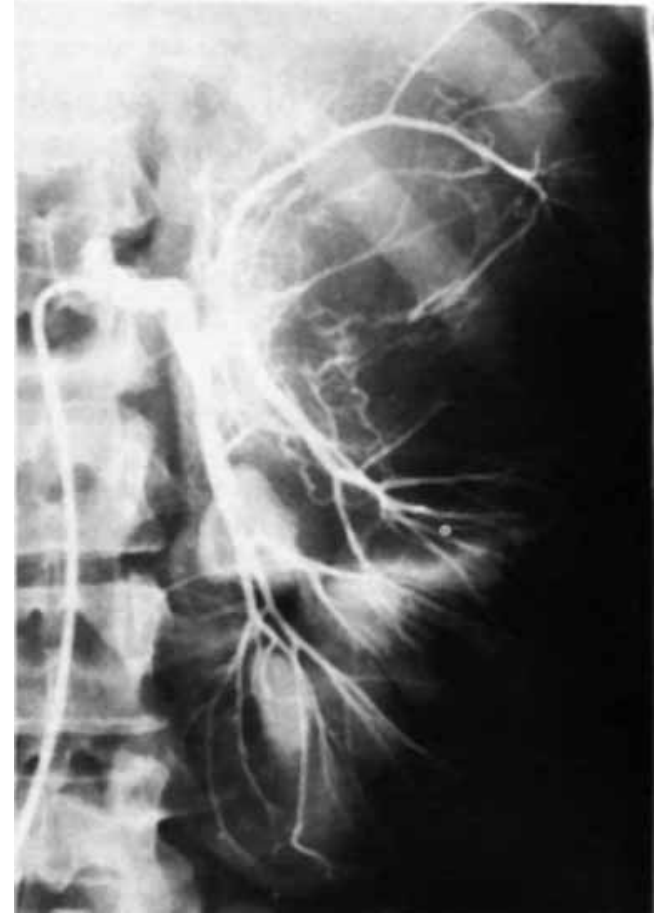

FIGURE 2A

FIGURE 2.-Renal angiogram in a 21 year old woman with an exophytic, slightly papillary, transitional cell carcinoma of the kidney.

A. Mid-arterial phase. Numerous, fine tumour vessels are associated with hydronephrosis.

B. Angiogram after intra-arterial administration of epinephrine. Note the relative lack of constriction of the tumour vessels to epinephrine. The encased arteries, with changing calibre and angulation, do not respond to epinephrine (arrow).

patients had angiographic findings of hydronephrosis, caused by tumour obstruction of the renal pelvis or the infundibulae.

7) Venous invasion (Figure 5). The overall incidence of venous invasion could not be evaluated in this series since only three patients showed either invasion or displacement of the veins. In one additional patient an occlusion of the main renal vein was shown in the venous phase of the renal angiogram.

As can be seen from Table 1, a combination of several of the above angiographic findings were present in the 15 patients in whom the diagnosis was made. These lesions were all larger than $2 \mathrm{~cm}$ in diameter and most were in the extrarenal portion of the renal pelvis. 


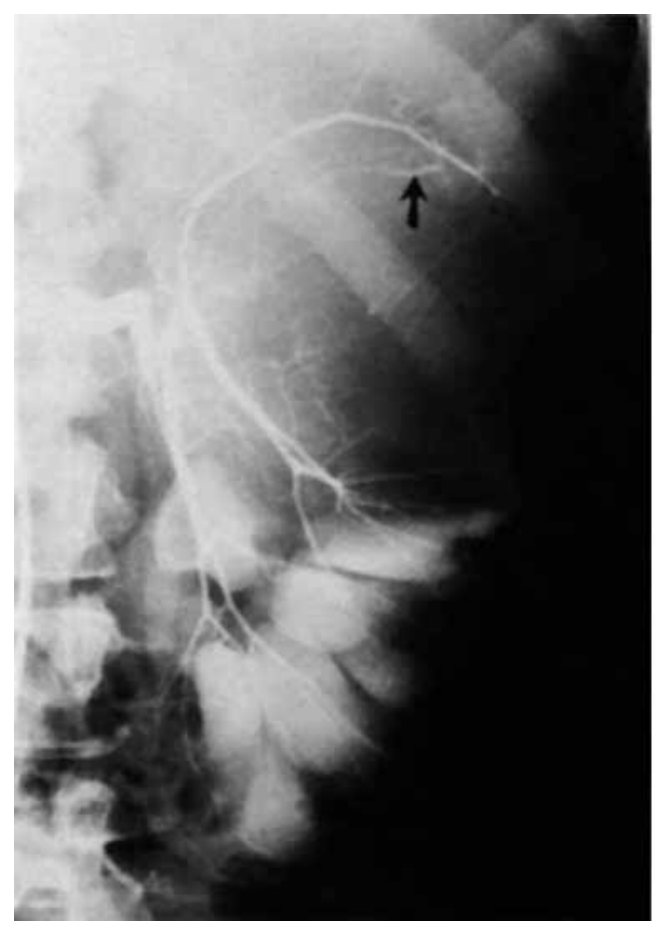

FIGURE 2B

In the four patients in whom epinephrine was given prior to angiography, the tumour vessels failed to constrict following epinephrine. In three patients fine tumour vessels were much better seen following epinephrine because of the marked vaso-constriction of the adjacent normal renal vessels (Figure 3C). The tumours were also better seen on angiograms following the administration of Priscoline, probably because of an increased amount of contrast accumulation in the tumour during the capillary phase.

\section{DISCUSSION}

The differential diagnosis of transitional cell carcimona of the kidney at angiography includes hypernephroma, metastatic carcinoma, nonopaque calculi, and several types of inflammatory disease. Hypemephromas are rarely a problem because they are generally hypervascular and occur in the renal parenchyma. They usually have vascular lakes within the tumour and some arteriovenous shunting; they are rarely supplied by pelviureteric arteries 9 . However, a poorly vascularized hypernephroma of the papillary type may very rarely simulate an infiltrating transitional cell carcinoma,

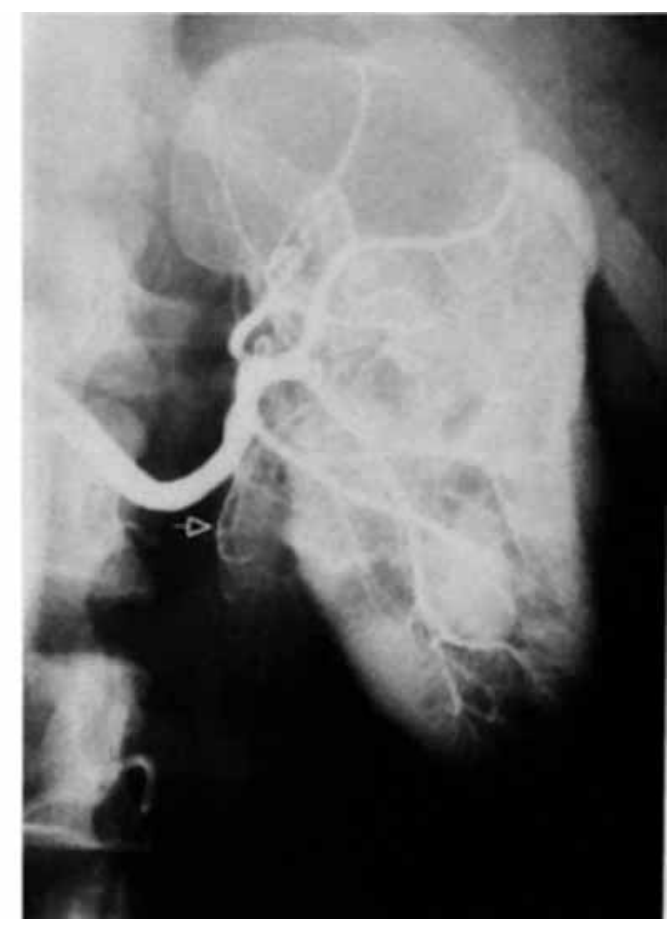

FIGURE 3A

FIGURE 3.-Renal angiograms in a 49 year old men with a diffusely infiltrating transitional cell carcinoma.

A. Arterial phase following the intra-arterial injection of $24 \mathrm{mgm}$ of Priscoline. Fine tumour vessels arise from the pelviureteric arteries (arrow).

B. Venous phase. Increased accumulation of contrast medium in the tumour (arrows) is associated with marked hydronephrosis of the upper pole.

C. An angiogram following epinephrine shows the neovascularity to be enhanced because of constriction of the normal intrarenal arterial branches.

particularly if it parasitizes blood flow from the areas that it infiltrates, including the renal pelvis and calyces. Metastatic carcinoma to the kidney is also frequently poorly vascularized ${ }^{2}$ and may give an angiographic appearance similar to transitional cell carcinoma, particularly the "pruned tree" appearance of the arterial branches and an ill-defined defect in a nephrogram phase, as shown in Figure 4B. They should not, however, cause the development of prominent pelviureteric arteries.

Nonopaque renal calculi can be a differential problem at both intravenous urography and angiography. At urography they may. appear as a fixed filling defect which may or may not cause obstruc- 


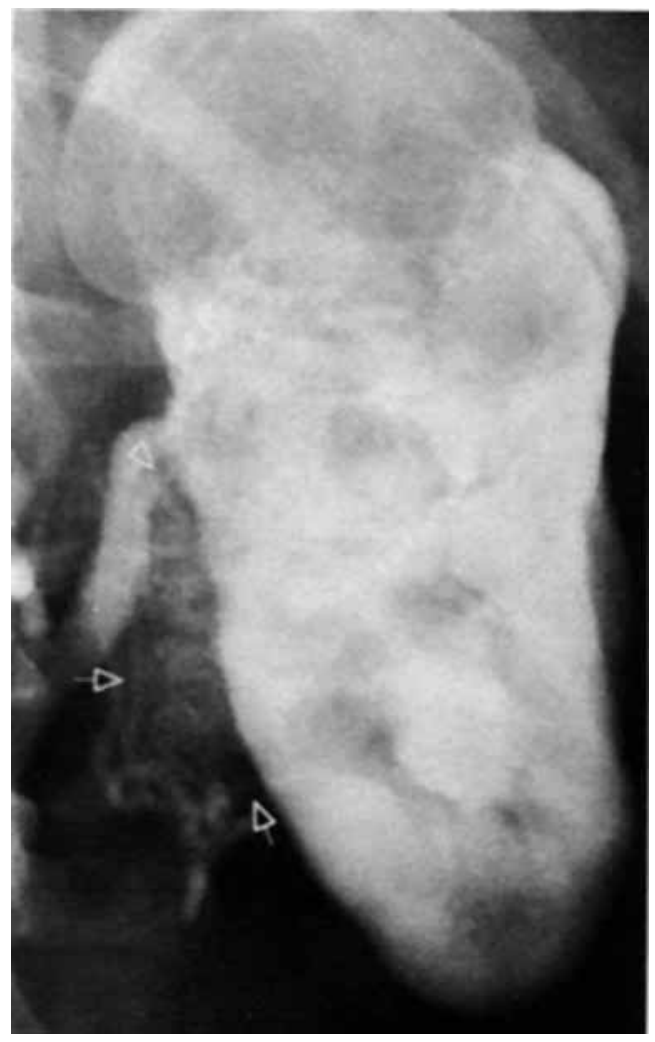

FIGURE 3B

tion and hydronephrosis. At angiography they frequently stimulate the formation of localized inflammatory reaction and an accompanying increase in fine vascularity and some dilatation of the pelviureteric arteries. Tumour vessels and infiltrated arteries, however, should not be seen.

Renal inflammatory diseases which are associated with pyonephrosis, such as xanthogranulomatous pyelonephritis or tuberculosis, may produce appearances similar to a transitional cell carcinoma. However, subtle differences should be present. In most of these conditions, a fine increase in vascularity occurs in the infected areas, and in tuberculosis the pelviureteric arteries may become dilated4. However, tumour neovascularity and encased arteries have not been observed in inflammatory disease. Gammil et al.3, analyzing 13 patients with xanthogranulomatous pyelonephritis found no neovascularity.

The use of pharmacoangiography may aid in the differential diagnosis of transitional cell car-

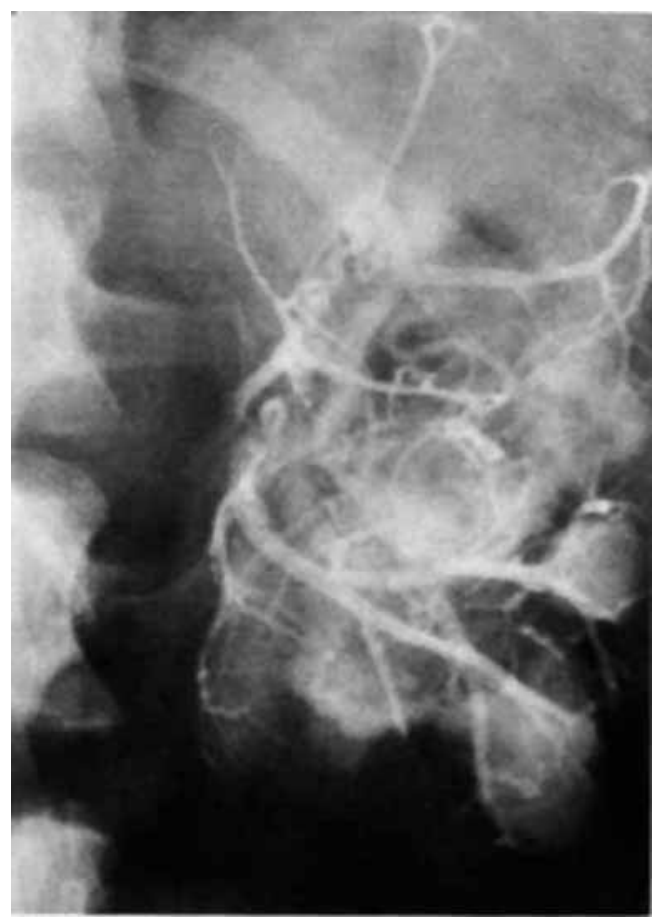

FIGURE 3C

cinomas. In our patients the tumour vessels were apparent without epinephrine, but the use of epinephrine enhanced their visualization. Moreover, the abnormal vessels seen in inflammatory diseases may constrict following the administration of epinephrine 3 although the general experience with epinephrine in the differential diagnosis of inflammatory disease and tumours is inadequate to state this for certain. Priscoline has been used to enhance the demonstration of poorly vascularized hypernephromas and may also have some value in the demonstration of these generally poorly vascularized transitional cell tumours.

The results of this group of patients indicate that the accuracy of angiography is not appreciably greater than intravenous urography and retrograde urography. However, the methods tend to be complementary. Retrograde urography has a greater accuracy in those patients with polypoid tumours in the renal calices and the intrarenal portion of the renal pelvis while angiography is of greater value in patients with nonfunctioning kidneys, which generally have complete obstruction. Angiography is generally used to assess the extent of the tumour and to exclude extension of 


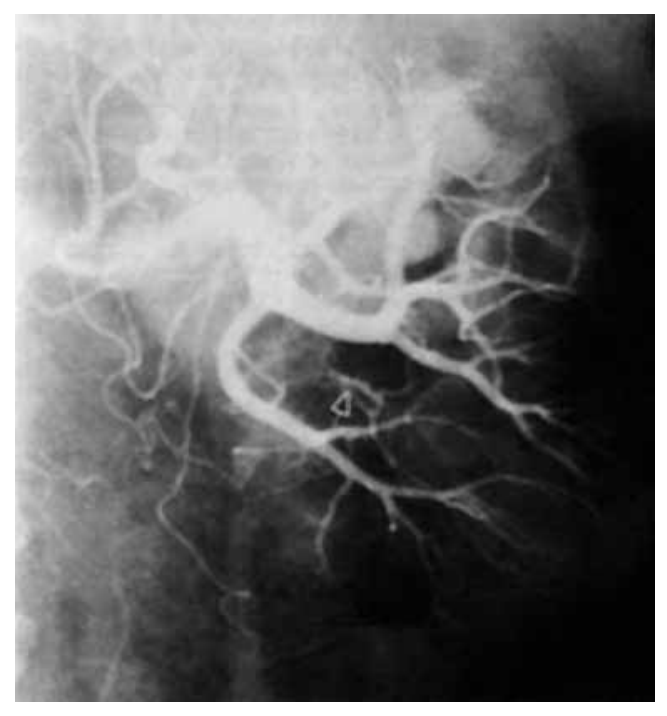

FIGURE 4A

FIGURE 4.-Renal angiogram in a 52 year old man with an infiltrating transitional cell carcinoma in the lower half of the left kidney.

A. Arterial phase. An interlobar branch is irregulariy encased (arrow). The lower half of the kidney has a "pruned-tree" appearance.

B. Venous phase. An ill-defined defect is present in the lower half of the kidney during nephrogram phase.

TABLE 1

Angiographic Findings in 20 Patients with Transitional Cell Carcinome of the Kidney

\begin{tabular}{l|c|c}
\hline Angiographic Findings & $\begin{array}{c}\text { Number } \\
\text { of } \\
\text { Patients }\end{array}$ & Percent \\
\hline A. Tumour Vessels & 15 & 75 \\
B. Tumour Stain & 11 & 55 \\
C. Prominent Pelviureteric & 13 & 65 \\
D. Arteries & 10 & 50 \\
E. Prterial Encasement & 4 & 20 \\
F. Defect in Nephrogram & 4 & 20 \\
G. Hydronephrosis & 5 & 25 \\
H. Venous Invasion or & 4 & 20 \\
\hline
\end{tabular}

the lesion into the renal veins and inferior vena cava even though the diagnosis has been made by urography.

\section{SUMMARY}

The spectrum of angiographic findings in 20 patients with transitional cell carcinomas of the

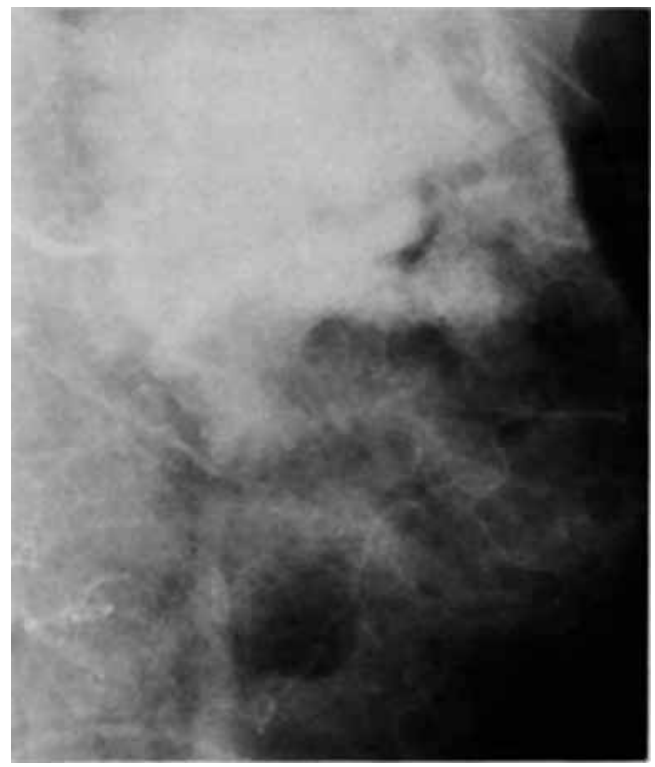

\section{FIGURE 4B}

kidney is described. In 15 of 20 patients (75\%), prospectivè diagnosis of transitional cell carcinomas were made because of a combination of the angiographic findings; tumour vessels, tumour stain, prominent pelviureteric arteries and arterial encasement. In 4 patients with negative angiograms the lesions were relatively small in size and were situated within the renal parenchyma, primarily involving the calyces. The use of pharmacoangiographic agents such as epinephrine and priscoline improved the angiographic visualization of transitional cell carcinomas of the kidney.

For the past several years angiography has had a central role in the evaluation of patients with hematuria and renal masses1, 5, 6, 7,8. Although the use of diagnostic ultrasound and renal puncture have eliminated angiography from the diagnosis of renal cysts, most renal masses which are solid or which have equivocal findings at ultrasound still undergo angiography. At the same time, the decreasing use of retrograde urography has resulted in more frequent angiography in patients with unilateral nonfunctioning kidneys. Transitional cell carcinomas of the renal pelvis are an important cause of both hematuria and nonfunctioning kidneys. We have therefore reviewed our material to reassess the angiographic abnormalities caused by the transitional cell carcinomas and the overall accuracy of the angiography in the diagnosis of these lesions. 


\section{K. J. CHO, S. R. REUTER AND P. R. HOSKINS}

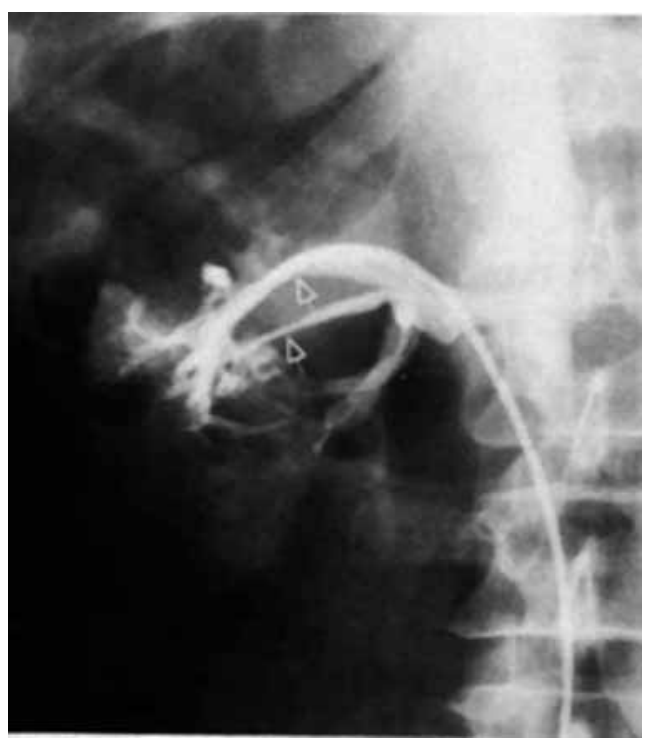

FIGURE 5.-Renal venogram in a 65 year old man with a transitional cell carcinoma of the renal pelvis. Seg mental veins are stretched and narrowed (arrows).

\section{REFERENCES}

1. Boijsen E. and Folin J. (1961). "Angiography in Carcinoma of the Renal Pelvis." Acta Radiol., $56: 81$.

2. Bosniak M. A., Stern W., Lopez F., Tehranian N. and OConnor S. J. (1969). "Metastatic Neoplasm to the Kidney. A Report of Four Cases Studied with Angiography and Nephrotomography." Radiology $92: 989$.

3. Gammill S., Rabinowitz J. G., Peace R., Sorgen St., et al. (1975). "New Thoughts Concerning Xanthogranulomatous Pyelonephritis (X-P)." Amer. J. Roentgenol, $125: 154$

4. Giustra P. E., Watson R. C., and Shulman H. (1971). "Arteriographic Findings in the Various Stages of Renal Tuberculosis." Radiology, 100 : 597.

5. Haleem S. A., Syrayregen S. and Siegelman S. S (1972). "Preoperative Diagnosis of Renal Pelvic Carcinoma." J. Urol 108:695.

6. Mitty H. A., Baron M. G. and Feller M. (1969). "Infiltrating Carcinoma of the Renal Pelvis." Radio$\log y, 92: 994$.

7. Pollen J. J., Levine E. and Van Blerk P. J. P. (1975) "The Angiographic Evaluation of Renal Pelvic Carcinoma." Brit. J. Urol, $47: 363$.

8. Rabinowitz J. G., Kinkhabwala M., Himmelfarb E. et al., (1972). "Renal Pelvic Carcinoma. An Angiographic Re-evaluation." Radiology, 102: 551.

9. Watson R. C., Fleming R. J. and Evans J. A. (1968) "Arteriography in the Diagnosis of Renal Carcinoma Review of 100 Cases." Radiology, 91 : 888 .

\section{SOCIETY OF CARDIOVASCULAR RADIOLOGY}

The Society of Cardiovascular Radiology announces its Third Annual Postgraduate Course on Diagnostic and Therapeutic Angiography and its Relationship to Other Imaging Modalities.

The course will be held at the Fairmont Hotel in New Orleans from February 20-23, 1978. The material to be covered includes daily symposia on the relationship of angiography to other imaging modalities, problems of thromboembolic disease, clinical applications of venous sampling, and interventional angiography. In addition, eight student participation workshops will be held each afternoon covering specific technical and clinical problems in angiography. The course is approved for 24 hours of Category 1 Credit by the American College of Radiology and the American Medical Association.

The tuition fee of $\$ 275.00$ includes luncheons with the faculty and coffee breaks, $\$ 175.00$ for residents and fellows. For further information and application blanks contact:

William J. Casarella, M.D.

Department of Radiology

Columbia-Presbyterian Medical Center

622 West 168th Street

New York, N.Y. 10032 